6.

Derecho administrativo 

Revista de Derecho

de la Pontificia Universidad Católica de Valparaíso XXIX (Valparaíso, Chile, $2^{\text {do }}$ Semestre de 2007)

[pp. 269 - 298]

\title{
EL DERECHO URBANÍSTICO, LOS INSTRUMENTOS DE PLANIFICACIÓN TERRITORIAL Y EL RÉGIMEN JURÍDICO DE LOS BIENES PÚBLICOS
}

\author{
[Urban Law, Instruments of Land Planning and the Legal \\ Regime of Public Property] \\ Eduardo Cordero Quinzacara* \\ Pontificia Universidad Católica de Valparaíso
}

\begin{abstract}
REsumen
El autor analiza la forma en que el Derecho urbanístico ha extendido su ámbito de acción, regulando la propiedad urbana e incidiendo en el régimen jurídico de los bienes públicos. En tal sentido, estudia la forma en que se articulan los instrumentos de planificación territorial con el régimen sectorial de los bienes públicos en Chile (costas, aguas, carreteras, calles, etc.), con el fin de dar cuenta de las formas de coordinación entre las diversas autoridades competentes sobre la materia y las falencias que existen en nuestro derecho. El autor concluye que el instrumento idóneo para implementar una política que garantice un aprovechamiento racional del uso suelo se debe encontrar en los instrumentos de planificación a nivel regional, como mecanismo de coordinación de la acción de las autoridades nacionales y locales con competencia transversal y sectorial.
\end{abstract}

Palabras Clave: Urbanismo - Planificación - Bienes públicos - Coordinación administrativa.

\begin{abstract}
The author analyses how urban law has expanded its reach by regulating urban property and by influencing on the legal regime of public property. The manner in which the land planning instruments are articulated with the sector regime of public property in Chile (coasts, water, highways, streets, etc.) is studied to explain the way the different pertinent authorities coordinate and the flaws in our law. The author finally concludes that the pertinent instrument to implement a policy to guarantee a rational use of the land must be found within the planning instruments at a regional level, as a coordinating mechanism of the action of the national and local authorities together with transversal and sector competency.
\end{abstract}

Keywords: Urbanism - Planning - Public property - Administrative coordination.

* Profesor de Derecho Administrativo en la Facultad de Derecho de la Pontificia Universidad Católica de Valparaíso. Dirección postal: Avenida Brasil 2950, Valparaíso, Chile. Correo electrónico: eduardo.cordero@ucv.cl 


\section{INTRODUCCIÓN**}

El urbanismo ha superado hace bastante tiempo el ámbito original en donde se ha gestado, esto es, la ciudad, y ha llegado a abarcar la ordenación de la totalidad del territorio. Tanto en los ordenamientos comparados como en el chileno no hay ningún espacio del territorio que quede fuera de las previsiones de la legislación urbanística y, por tanto, sujeto a la intervención de la Administración pública. Esta fuerza expansiva de la noción urbanística se aprecia claramente en el alcance que han ido adquiriendo los planes de ordenación urbana sobre el territorio y la técnica de la autorización edificatoria concretada en las licencias urbanísticas o permisos, que hasta época reciente comprendían un número determinado de actividades, para llegar a aplicarse a la globalidad de acciones humanas que se realizan sobre el suelo, independiente a la calidad o naturaleza del sujeto actuante, que puede ser tanto privado como público. Así, la cota máxima ha sido el sometimiento de las obras realizadas por el Estado y los diversos organismos públicos a las previsiones urbanistas ${ }^{1}$.

** Abreviaturas: Cag = Código de Aguas; CC. = Código Civil; CGR = Contraloría General de la República; CPR. = Constitución Política de la República ; DCGR = Dictamen de la Contraloría General de la República; DDU = Dirección de Desarrollo Urbano; DFL. $=$ Decreto con fuerza de ley; DL. $=$ Decreto ley; DoM. $=$ Dirección de Obras Municipales; Ds. = Decreto supremo; LBGMA. = Ley No 19.300, de Bases Generales del Medio Ambiente; LGPA. = Ley General de Pesca y Acuicultura; LGSE. = DFL. No 4/2007, Ley General de Servicios Eléctricos; LGUC. = DFL. N 458/1976, Ley General de Urbanismo y Construcciones; LOCBGAE. = DFL. N ${ }^{\circ} 1 / 2001$, del Ministerio Secretaría General de la Presidencia, que fija el texto refundido, coordinado y sistematizado de la Ley N ${ }^{\circ}$ 18.695, Orgánica Constitucional de Bases Generales de la Administración del Estado; LOCGAR. $=$ DFL. $\mathrm{N}^{\circ} 1 / 2005$, del Ministerio del Interior, que fija el texto refundido, coordinado y sistematizado de la Ley $\mathrm{N}^{\circ} 19.175$ Orgánica Constitucional de Gobierno y Administración Regional; LOCM. = DFL. N ${ }^{\circ} 1 / 2006$, del Ministerio del Interior, que fija el texto refundido, coordinado y sistematizado de la Ley $\mathrm{N}^{\circ} 18.695$, Orgánica Constitucional de Municipalidades; LOMOP. = DFL. N 850/1997, Ley Orgánica del Ministerio de Obras Públicas; MINVU = Ministerio de Vivienda y Urbanismo; MO = Ministerio de Obras Públicas; OGuc. = Ds. No 47/2000, del Ministerio de Vivienda y Urbanismo, que fija el texto de la Ordenanza General de Urbanismo y Construcciones; PRC $=$ Plan Regulador Comunal; PRDU = Plan Regional de Desarrollo Urbano; PRI = Plan Regulador Intercomunal; SEREMI = Secretaría Regional Ministerial.

${ }^{1}$ Sobre el alcance del urbanismo en la actualidad se pueden consultar algunas obras generales como las de Fernández, Tomás Ramón, Manual de Derecho Urbanístico (140 edición, Madrid, El Consultor, 1999); García DE ENTERría, Eduardo - Parejo Alfonso, Luciano, Lecciones de Derecho urbanistico (2 edición, Madrid, Civitas, 1981); del mismo Parejo Alfonso, Luciano, Derecho urbanístico. Instituciones básicas (Buenos Aires, Ciudad Argentina, 1986). En nuestro país enuncia esta situación Ríos Alvarez, Lautaro, El urbanismo y los principios fundamentales del 
La evolución de la ordenación urbanística ha estado influida a partir del siglo XIx por la realización de grandes obras de infraestructuras; el acelerado proceso de urbanización; la congestión de los núcleos urbanos y, sobre todo, por las tensiones derivadas de la presión concurrente sobre un mismo territorio de distintos usos y competencias de los órganos públicos. De hecho, las primeras normas urbanísticas sólo eran de aplicación a los administrados o particulares, en ningún caso se contemplaba la posibilidad de adoptar similares exigencias respecto del Estado o los entes públicos. Además, una parte importante del suelo era considerado un verdadero "espacio inmune" cuya gestión y planificación quedaban en manos de órganos sectoriales de la Administración, a los cuales no llegaban las competencias urbanísticas.

Esta es la situación que ha afectado a una parte importante de los bienes que integran lo que se ha denominado el dominio público o bienes públicos ${ }^{2}$, al punto que la ordenación urbanística quedaba subordinada

Derecho urbanistico (prólogo de Francisco González Navarro, Madrid, Ministerio para las Administraciones Públicas, 1985) y en época reciente Figueroa Velasco, Patricio y Figueroa Valdés, Juan Eduardo, Urbanismo y Construcción (Santiago, LexisNexis, 2006).

${ }^{2}$ Utilizaremos la expresión de bienes públicos en lugar de dominio público, que es la denominación más o menos asentada en los sistemas jurídicos que reconocen una filiación con el sistema de la Europa continental. Por lo demás, la institución del dominio público tal como se ha elaborado por la doctrina francesa y española, no es totalmente asimilable con el régimen de los bienes públicos en Chile, que se construye a partir de las normas constitucionales (artículo 19 No 23 Const.) y civiles (artículos 589 y ss. cc.). En el Derecho chileno sólo tienen la calidad de bienes públicos (o bienes nacionales de uso público) aquellos cuyo uso pertenece a todos los habitantes de la Nación. Sobre el particular, ante la abundante bibliografía existente, se puede tener una visión panorámica consultando los trabajos de FonT i Llovet, Tomás, La protección del dominio público en la formación del Derecho administrativo español: potestad sancionadora y resarcimiento de daños, en Revista de Administración Pública 123 (septiembre-diciembre, 1990); del mismo autor, La ordenación constitucional del dominio público, en MartíN-Retortillo, Sebastián (coordinador), Estudios sobre la Constitución Española. Homenaje al profesor Eduardo García de Enterría (Madrid, Civitas, 1991); con una muy buena síntesis en Morillo-Velarde Pérez, José Ignacio, Dominio público (Madrid, Trivium, 1992); y uno de los trabajos de mayor influencia de Parejo Alfonso, Luciano, Dominio público: un ensayo de reconstrucción de su teoría general, en Revista de Administración Pública 100-102 (enero-diciembre, 1983). También se puede ver una visión global del régimen español en SÁNCHEz Morón, Miguel (dir.), Los bienes públicos. Régimen jurídico (Madrid, Tecnos, 1997). Por su parte, en Chile bien se puede consultar los trabajos de Montr Oyarzún, Santiago, El Dominio público. Estudio de su régimen especial de protección y utilización (Santiago, ConoSur, 2001); y Vergara Blanco, Alejandro, La summa divisio de bienes y recursos naturales en la Constitución de 1980, en Navarro Beltrán, Enrique (coord.), 20 
a la planificación y actuación pública sectorial que recaía sobre dichos bienes. Así, un conjunto de determinaciones de naturaleza e incidencia claramente urbanística eran adoptadas, en definitiva, al margen del plan y con una visión parcial de las necesidades y requerimientos territoriales. La acción urbanística se encontraba seriamente limitada en su función de encauzar y regular el crecimiento de las ciudades al servicio de una determinada política del suelo y ordenación urbana que permitiera un desarrollo territorial equilibrado.

Ahora bien, para iniciar nuestro estudio debemos señalar que la naturaleza y peculiaridades que asume este conjunto de bienes hace que sea del todo conveniente adoptar un análisis sistemático que nos permita arribar a conclusiones seguras, sobre todo tratándose de una ordenación del espacio, que claramente tendrá que enfrentar este excepcional y fragmentado régimen.

En tal sentido, la distinta naturaleza de los bienes públicos hace que la forma en que se vinculan o relacionan con los instrumentos de planificación urbanística sea diversa. A pesar de no ser resaltada en toda su dimensión, una de las primeras funciones que cumple la ordenación urbana es la segregación o división del suelo en dos estatutos básicos, como es el régimen ordinario de la propiedad y el exorbitante de los bienes públicos. El desarrollo del proceso urbanístico no sólo culmina con la producción de suelo edificable o solares -sometida al régimen de la propiedad-, sino también de bienes públicos como viales, espacios libres, zonas verdes y dotaciones públicas de carácter local que estarán al servicio de los suelos que se urbanizarán. Estos espacios estarán sujetos al régimen de los bienes públicos, pero con la peculiaridad de que su previsión, afectación y obtención estarán dentro de la lógica del sistema urbano que diseña el plan. Para denominar a este conjunto de bienes (o suelo afectado) utilizaremos la expresión de bien público local, en el sentido que surgen o son asumidos por modelo territorial previsto por el plan.

Por otra parte, la legislación sectorial contempla un conjunto de bienes que también son considerados de bienes públicos y que tienen una clara incidencia territorial, como ocurre con las costas, carreteras y aguas, pero que se encuentran fuera de las determinaciones de plan o son asumidos por éste como un elemento externo que debe ser integrado dentro de la

años de la Constitución chilena 1981-2001 (Santiago, ConoSur, 2001); del mismo autor, La Teoría del dominio público. El estado actual de la cuestión, en Revista de Derecho Público 114 (Madrid, 1989), y Naturaleza jurídica de los "bienes nacionales de uso público", en Ius Publicum 3 (Santiago, 1999), entre otras. No obstante, debemos dejar en claro que no compartimos la tesis de que el dominio público sea una categoría dogmática plenamente asimilable a los bienes nacionales. 
lógica y los objetivos de la ordenación espacial. Esta categoría de bienes es la que genera las mayores dificultades al momento de elaborar un plan y, especialmente, al ejecutarlo, ya que plantean una serie de conflictos competenciales y de intereses públicos concurrentes. Aludiremos a estos bienes también con la denominación de bien público sectorial, en la medida que su régimen jurídico se encuentra en las llamadas leyes sectoriales.

\section{LOS BIENES PÚBLICOS LOCALES Y SU ORDENACIÓN}

En Chile se atribuye a las municipalidades la administración de los bienes nacionales de uso público, incluido el subsuelo, existente en la comuna, salvo que, en atención de su naturaleza o fines y en conformidad a la ley, la administración de estos bienes corresponda a otros órganos de la Administración del Estado [artículo 5o letra c) Locm.]. Así, todos los bienes nacionales de uso público, sean naturales o artificiales, existente en el territorio municipal son administrados y conservados, en principio, por las municipalidades, salvo que expresamente se asigne esta tarea a otro órgano de la Administración del Estado. Sin embargo, en la práctica el alcance de esta disposición es más limitado, pues sólo quedan bajo la competencia de las municipalidades -salvo alguna excepción- los bienes públicos locales. La titularidad del resto de los bienes públicos se atribuye a otros órganos de la Administración ${ }^{3}$.

Ahora bien, en principio estos bienes no plantean mayores problemas respecto de su ordenación dentro del marco de los planes urbanísticos, pues existe una identidad plena entre el planificador y el titular demanial, que en este caso es la Municipalidad.

Por su parte, la Legislación urbanística prevé la obtención de estos bienes a través de dos vías: i) Expropiación, que comprende los inmuebles necesarios para la formación de áreas de uso público y equipamiento (artículo 83 LGUC.). Para tal efecto, el artículo 59 LGUC. declara de utilidad pública todos los terrenos consultados en el Plan Regulador Comunal destinados a calles, plazas, parques u otros espacios de tránsito público, incluso sus ensanches; ii) Cesión gratuita, según el artículo 79 LGUC. en toda urbanización de terrenos se cederá gratuita y obligatoriamente para circulación, áreas verdes, desarrollo de actividades deportivas y recreacionales, y para equipamiento, las superficies

\footnotetext{
${ }^{3}$ Así, por ejemplo, la administración y conservación de los caminos públicos, es asignada a la Dirección de Vialidad del Ministerio de Obras Públicas (artículo 18 LOMOP.); las aguas a la Dirección de Aguas del mismo Ministerio (artículo 23 LOMOP.y artículos 298 y ss. CAg.); y las playas, terrenos de playa y roqueríos a la Subsecretaría de Marina del Ministerio de Defensa Nacional (DFl. No 340 sobre Concesiones Maritimas, de 1960).
} 
que señale la OGUC., las que no podrán exceder del $44 \%$ de la superficie total del terreno original. ${ }^{4}$ De acuerdo al artículo 135 LGUc., cuando la Dirección de Obras Municipales acuerde la recepción de las obras de urbanización, se considerarán, por este solo hecho, incorporadas al dominio nacional de uso público todas las calles, avenidas, plazas y espacios públicos en general, que existieren en la nueva zona urbanizada.

Respecto del uso y disfrute de estos bienes, el sistema de bienes públicos que rige en Chile determina que sólo tienen esta calidad los bienes que estén destinados al uso de todos los habitantes de la Nación. Por tal razón, la regla general es que su uso sea general o común. Sin embargo, el artículo 32 LOCM. prevé la posibilidad de conceder el uso privativo de los bienes nacionales de uso público que administran las municipalidades a través de permisos o concesiones. La diferencia entre ambos tipos de actos no radica en la naturaleza del uso que confieren -ambos otorgan un derecho exclusivo sobre el uso de dichos espacios-, sino en la naturaleza de los derechos que otorgan. Así, los permisos son esencialmente precarios y pueden ser modificados o dejados sin efecto, sin derecho a indemnización, mientras que la concesión confiere un derecho al uso preferente del bien, el cual puede ser revocado cuando sobrevenga un menoscabo o detrimento grave al uso común o cuando concurran otras razones de interés público. En este caso, el concesionario tiene derecho a ser indemnizado de los perjuicios que le ocasione el término anticipado, salvo que éste se haya producido por el incumplimiento de sus obligaciones.

Los Planes Reguladores no sólo pueden prever la afectación del suelo, sino también su desafectación. En tal sentido, el artículo 61 LGUC. dispone que la desafectación de bienes nacionales de uso público se tramitará como una modificación del Plan Regulador 5 .

${ }^{4}$ Vid. artículo 2.2.5 OGUC.

${ }^{5}$ Vid. Circular Ord. No 0363, de 13 de julio de 2001, DDu 87. Esta circular señala que la desafectación de bienes nacionales de uso público puede ser dispuesta por dos vías diferentes, una como modificación del Plan Regulador, conforme a lo dispuesto en el artículo 61 LGUC., norma que se encuentra plenamente vigente en la actualidad, y la otra, por decreto supremo del Ministerio de Bienes Nacionales dado su carácter de administrador de los bienes del Estado y de la facultad de disposición de los mismos que le franquea la ley. La desafectación por el Ministerio de Bienes Nacionales se encuentra consagrada expresamente en el inciso segundo del artículo 64, del DL. No 1939, de 1977, sobre Adquisición, Administración y Disposición de Bienes del Estado, que dispone que por razones fundadas pueden desafectarse de su calidad de uso público determinados inmuebles, lo que, al tenor de los incisos primero y segundo del mismo precepto, debe llevarse a la práctica mediante la dictación de un decreto supremo del Ministerio de Bienes Nacionales. 


\section{LOS BIENES PÚBLICOS SECTORIALES \\ Y LOS INSTRUMENTOS DE PLANIFICACIÓN TERRITORIAL}

\section{Los bienes públicos y su alcance.}

Tal como ya lo hemos señalado, en el Derecho chileno sólo tienen la calidad de bienes públicos (o bienes nacionales de uso público) aquellos cuyo uso pertenece a todos los habitantes de la Nación. Estos bienes nacionales comprenden tanto los bienes públicos locales como sectoriales. Sin embargo, en esta parte nos limitaremos a analizar los bienes nacionales de uso público sectoriales, es decir, aquellos que no forman parte de los bienes públicos locales, y que ya hemos tenido ocasión de mencionar in supra.

Los bienes nacionales de uso público sectoriales pueden ser naturales, en la medida que su publicación se realiza como categoría de bienes aludiendo a sus características físicas, como el mar adyacente (artículo 593 CC.), las playas (artículo $594 \mathrm{CC}$.), las aguas que corren por cauces naturales (inciso $1^{\circ}$ del artículo 595 cc. y artículo $6^{\circ} \mathrm{CAg}$.), los álveos o lechos de ríos o lagos (artículo 30 cag.) y los grandes lagos (inciso $1^{\circ}$ del artículo 596 cc.); o artificiales, que son producto de la obra o artificio del ser humano y que deben ser planificados, construidos y afectados de forma individual o concreta, como ocurre con los caminos públicos y los puentes (artículo 582 incisio $2^{\circ}$ CC. y artículo 25 LOMOP.).

En Chile no son bienes públicos los puertos ni los aeropuertos. Esto se debe a que el criterio determinante para hacer esta calificación lo constituye el uso común y general de los mismos, condición que no cumplen ambos tipos de infraestructura, porque respecto de ellas cobra mayor importancia el servicio público al cual dan soporte material. De esta forma, tanto los puertos como los aeropuertos son bienes fiscales o patrimoniales del Estado, lo cual no impide que existan puertos y aeropuertos privados. No obstante, a pesar de ser bienes de titularidad patrimonial del Estado (cuestión totalmente incompatible con los bienes nacionales de uso público), esto no obsta a que se les aplique algunas reglas de excepción, como ocurre con la inembargabilidad de los mismos, considerando que se encuentran afectados esencialmente a un servicio público y cuya perturbación puede ocasionar serios perjuicios a los intereses públicos comprometidos en la prestación de dicho servicio. Además, su planificación y posterior construcción están sujetas a los mismos procedimientos y normas de los bienes nacionales de uso públicos sectoriales, como las carreteras y los puentes, debido a la envergadura de dichas infraestructura, así como por su impacto territorial.

Para comprender mejor la forma en que se insertan los bienes públicos sectoriales en el marco de la ordenación urbana, es necesario dar cuenta de la forma como se estructura la Administración pública en materia urbanística y la manera como se articulan los diversos instrumentos de 
ordenamiento territorial.

\section{La forma unitaria del Estado chileno y su influencia en la organización} de la Administración urbanistica.

En la articulación de los instrumentos de planificación territorial entre sí y respecto de los bienes públicos sectoriales influye claramente la forma de unitaria del Estado (artículo $3^{\circ} \mathrm{CPR}$. .).

En Chile el Gobierno y la administración del Estado corresponde al Presidente de la República, quien es, además, el Jefe de Estado. Estas funciones las realiza con la colaboración de los órganos de la Administración del Estado, constituida por los Ministerios, las Intendencias, las Gobernaciones y los órganos y servicios públicos creados para el cumplimiento de la función administrativa, incluidos la Contraloría General de la República, el Banco Central, las Fuerzas Armadas y las Fuerzas de Orden y Seguridad Pública, las Municipalidades y las empresas públicas creadas por ley (artículos 24 CPR. y 1 LOCBGAE.).

Dentro de este complejo orgánico, las competencias urbanísticas se atribuyen en diversos niveles:

i) Dentro de la Administración central, se atribuyen competencias al Ministerio de Vivienda y Urbanismo (órgano desconcentrado funcionalmente) y a las Secretarías Regionales Ministeriales de Vivienda y Urbanismo (órganos desconcentrados territorialmente a nivel regional).

ii) A nivel regional, a los Gobiernos Regionales (órganos descentralizado territorialmente a nivel regional).

iii) A nivel comunal, a las Municipalidades (órganos descentralizados territorialmente a nivel comunal).

De esta forma, la política urbanística en Chile es el resultado de una acción administrativa que descansa tanto en la unidad organizativa como procedimental. No cabe duda de que son las municipalidades las que cumplen un papel fundamental respecto de la ordenación urbanística, no sólo en la elaboración de los instrumentos de planificación territorial, sino también en la fase de ejecución de planes reguladores y de su control a través de la intervención preventiva de la edificación y uso del suelo (licencias, órdenes de ejecución, ruina, protección de la legalidad urbanística, parcelaciones e inspección urbanística) y en la aplicación de infracciones y sanciones. Esto no impide que se instrumenten una serie de mecanismos destinados a articular las diversas competencias (no sólo urbanísticas sino también sectoriales), proceso facilitado por una Administración fuertemente centralizada.

3. La articulación de los instrumentos de planificación urbanistica en 


\section{Chile: la cláusula de prevalencia.}

No existe en Chile un único instrumento de planificación urbanística, sino que hay múltiples instrumentos que cumplen tal objetivo. La característica común de todos es su carácter "horizontal", pues comprenden objetivos globales que permitan el desarrollo integral y armónico del sistema de asentamientos humanos. Además, cada uno tiene un ámbito diverso de extensión territorial (nacional, regional, intercomunal y comunal).

La forma unitaria del Estado chileno también influye decididamente en el sistema de planes urbanísticos. En primer lugar, a través de la intervención en el procedimiento de elaboración no sólo de las entidades territoriales (Gobierno Regional y municipalidades), sino también de la Administración central (MINVU y SEREMI). En segundo lugar, mediante la introducción de una cláusula de prevalencia a favor de los instrumentos que tienen un mayor nivel ${ }^{6}$, lo que desplaza el poder de decisión desde las entidades locales al poder central.

La LGUC. contempla un sistema de planificación urbana a nivel nacional $^{7}$. Sin embargo, nunca se ha aprobado un instrumento de esta naturaleza, ni ha sido considerado dentro de los instrumentos de planificación territorial contemplados en la oguc. Por tales razones, en Chile se ha optado por su sustitución a través de "Políticas Nacionales de Desarrollo Urbano", bajo la forma de una circular directiva que tiene por función fijar objetivos que guíen la actuación de los órganos a los cuales se les atribuye potestades sectoriales de incidencia territorial, así como a las entidades territoriales, que deben coordinar su actuación con las políticas nacionales ${ }^{8}$.

${ }^{6}$ Los diversos niveles de regulación en que se estructura el Derecho Urbanístico chileno hacen que la integración de los Instrumentos de Planificación Territorial se haga a partir del principio de prevalencia. Por tal razón, el artículo 2.1.1. oguc. dispone que las normas de la LGUC. y de la OGUC. priman sobre las disposiciones contempladas en los Instrumentos de Planificación Territorial que traten las mismas materias. Asimismo, estos instrumentos constituyen un sistema en el cual las disposiciones del instrumento de mayor nivel, propias de su ámbito de acción, tienen primacía y son obligatorias para los de menor nivel. Es decir, la jerarquía superior corresponde al Plan Regional de Desarrollo Urbano, seguido del Plan regulador intercomunal ó metropolitano, del Plan regulador comunal y de los Planes seccionales.

${ }^{7}$ Artículo 29 LGUC.

${ }^{8}$ Este instrumento es dictado conforme a lo dispuesto en el art. 8 del DL. No 1.305 que encomienda al Ministro de Vivienda y Urbanismo "la formulación de la politica nacional habitacional y urbanistica del Gobierno". Sin embargo, la última política nacional de desarrollo urbano ha sido sancionada en el año 1985 (DS. No 31, de 4 de marzo de 1985), encontrándose totalmente superada por la realidad social, política, cultural y económica existente actualmente en el país, así como por un conjunto de normas que tienden a abandonar este instrumento y a radicar tales 
En definitiva, en Chile son "Instrumentos de Planificación Territorial" los siguientes': i) El Plan Regional de Desarrollo Urbano; ii) El Plan Regulador Intercomunal o Metropolitano; iii) El Plan Regulador Comunal; iv) El Plan Seccional; y v) El Límite Urbano.

a) El Plan Regional de Desarrollo Urbano (PRDU). Este instrumento orienta el desarrollo de los centros urbanos de las regiones. Está conformado por una memoria explicativa ${ }^{10}$, los lineamientos de desarrollo urbano regional y los planos que grafiquen el contenido del plan. Como consecuencia de una política de modernización en materia de desarrollo urbano y territorial iniciada en el año 2002, en la actualidad todas las regiones han elaborado su PRDU, de los cuales dos ya se encuentran vigentes y once se encuentran en la última etapa de aprobación ${ }^{11}$.

El PRDU debe ser elaborado por la SEREMI respectiva, y debe someterse al sistema de evaluación de impacto ambiental, siendo aprobado previa opinión del Gobierno Regional [artículo 21 f) LOCGAR.], mediante decreto supremo del minvu dictado por orden del Presidente de la República. Uno de los efectos más importantes de los PRDU es que sus disposiciones deben "incorporarse a los planes reguladores intercomunales, metropolitanos y comunales" (artículo 33 LGUC.).

b) El Plan Regulador Intercomunal o Metropolitano. Estos instrumentos regulan el desarrollo físico de las áreas urbanas y rurales de diversas comunas que, por sus relaciones, se integran en una unidad urbana. Cuando el número de habitantes comprendido dentro de dicha unidad sea superior a los 500.000 le corresponderá la categoría de área metropolitana

decisiones en el nivel regional.

${ }^{9}$ Artículos 1.1.2 y 2.1.1 OGUC.

${ }^{10}$ De acuerdo a lo dispuesto por el artículo 2.1.5. OgUC., la Memoria Explicativa debe contener lo siguiente: i) Aspectos conceptuales y técnicos que justifican el Plan, tales como objetivos, fundamentos y metodología empleada, así como los antecedentes necesarios para dar cumplimiento a la Ley de Bases Generales del Medio Ambiente; ii) Estudios y antecedentes técnicos que sirvieron de base a la formulación del diagnóstico; iii) Diagnóstico que, a partir de la identificación de tendencias, permite analizar las fortalezas y debilidades para proponer alternativas de estructuración territorial, considerando grados de habitabilidad del territorio, jerarquía de los sistemas de centros poblados, sus áreas de influencia recíproca y relaciones gravitacionales; iv) Alternativas de estructuración analizadas; v) Agenda operativa en materias de planificación y requerimientos de inversión; vi) Los principales anteproyectos o proyectos de inversión previstos por el sector público; y vii) Los principales proyectos de inversión del área privada que hayan aprobado un estudio de impacto ambiental.

${ }^{11}$ Programa de actualización de instrumentos de planificación territorial 20022007 (Santiago, Ministerio de Vivienda y Urbanismo, División de Desarrollo Urbano, Departamento de Planificación Urbana, 2007). 
para los efectos de su planificación (artículo 34 LGC.). Por tal razón, estos instrumentos se denominan "Plan Regulador Intercomunal" (en adelante PRI) o "Plan Regulador Metropolitano" (PRM) respectivamente.

Estos instrumentos de planificación territorial están condicionados, principalmente, por el fenómeno de la conurbación. De esta manera, el límite del suelo urbano de dos o más comunas es al mismo tiempo el límite comunal de las mismas, sin perjuicio de que existan áreas rurales en algunos de estos espacios. Esto ha servido, además, para poder planificar las áreas rurales, como primer paso dentro de una política de ordenación de todo el territorio.

Tanto el PRI como PRM deben ser elaborados por la SEREMI de Vivienda y Urbanismo, con consulta a las municipalidades correspondientes e Instituciones Fiscales que se estime necesario. No obstante, con previa autorización de la SEREMI correspondiente, un grupo de municipalidades afectas a relaciones intercomunales podrán confeccionar directamente un Plan Regulador Intercomunal, el que deberá ser aprobado por dicha Secretaría. Este proyecto también debe ser sometido al sistema de evaluación de impacto ambiental [artículo $10 \mathrm{~h}$ ) LBGMA.]. Cumplido estos trámites se debe remitir el proyecto a la División de Desarrollo Urbano del MINvu para su revisión e informe técnico. Luego es enviado al Gobierno Regional con todos sus antecedentes para su aprobación (artículo $36 \mathrm{c}$ ), inciso $2^{\circ}$, LOCGAR. ${ }^{12}$. El proyecto aprobado debe ser promulgado por el Intendente [artículo 24 o) LOCGAR.] mediante una resolución, la que está sujeta al trámite de toma de razón ${ }^{13}$.

El sistema de prevalencia que se le confiere a los PRIs y a los PRMS adquiere una especial connotación respecto de los PRCs, que producen los siguientes efectos ${ }^{14}$ : i) Las disposiciones de estos instrumentos son obligatorias en la elaboración de los PRCs; ii) Las disposiciones de los PRIS que constituyan alteraciones a las disposiciones de los PRCs se entenderán automáticamente incorporadas a éstos como modificaciones; y iii) Por último, estos instrumentos se aplican supletoriamente a las comunas que carezcan de PRC.

c) El Plan Regulador Comunal (PRC). La Comuna es la unidad administrativa mínima a través de la cual se divide el país y fija los límites territoriales de las competencias municipales. En este ámbito es donde

${ }^{12}$ La Contraloría ha sostenido que los Gobiernos Regionales sólo pueden aprobar o rechazar el proyecto de PRI, no estando dentro de sus facultades la introducción de modificaciones. Vid. por todos dictamen $15.466 / 95$.

${ }^{13}$ Artículo 3 No 24 resolución No 520/96, CGR.

${ }^{14}$ Artículo 37 y 38 LGUC. 
se lleva cabo el nivel de planificación de mayor fuerza normativa. La Planificación Urbana Comunal es aquélla que promueve el desarrollo armónico del territorio comunal, en especial de sus centros poblados, en concordancia con las metas regionales de desarrollo económico-social, y se realiza a través del Plan Regulador Comunal (PRC) ${ }^{15}$.

El PRC es un instrumento normativo que tiene por objeto establecer las adecuadas condiciones de higiene y seguridad en los edificios y espacios urbanos, y de comodidad en la relación funcional entre las zonas habitacionales, de trabajo, equipamiento y esparcimiento (artículo 41 inciso $3^{\circ}$ LGUC.). Su objetivo primordial es "asignar usos" del suelo con el objeto de promover un desarrollo armónico del territorio comunal. Por tal razón, sus normas se refieren al uso del suelo o zonificación, localización del equipamiento comunitario, estacionamiento, jerarquización de la estructura vial, fijación de límites urbanos, densidades y determinación de prioridades en la urbanización de terrenos para la expansión de la ciudad, en función de la factibilidad de ampliar o dotar de redes sanitarias y energéticas, y demás aspectos urbanísticos (inciso final del artículo 41 LGUC.).

El PRC es confeccionado por la Municipalidad respectiva. Una vez que se ha elaborado el proyecto, el Alcalde, mediante decreto, debe fijar la fecha y lugar en que se expondrá al público el proyecto de Plan Regulador Comunal, con lo que se da inicio al trámite de aprobación. La LOCM. impone al Alcalde el deber de informar del proyecto al Consejo Económico y Social Comunal (CESCO). Este proyecto también está sometido al sistema de evaluación de impacto ambiental.

Cumplidos cada uno de los trámites enunciados, el Concejo Municipal debe entrar a conocer y pronunciarse del proyecto. Cuando el proyecto ha sido aprobado por el Concejo debe ser remitido a la SEREMI de Vivienda y Urbanismo para que elabore un informe técnico sobre el mismo. Luego se debe remitir el proyecto con todos sus antecedentes al Gobierno Regional, a fin de que sea aprobado por el Consejo Regional [artículo 36 c) LOCGAR.]. El Plan debe ser promulgado por resolución del Intendente [artículo 24 o) LOCGAR.], la cual está sujeta al trámite de toma de razón por parte de la CGR (artículo 3 No 24, resolución No 520/96 CGR).

d) Los Planes seccionales. La necesidad de una regulación detallada de los usos y trazado exacto de calles da lugar a la figura de los "planes seccionales". Los planes seccionales son instrumentos de regulación del uso del suelo a través de los cuales se desarrolla un PRC o se lleva a cabo una ordenación autónoma de una parte o sector del territorio municipal [incisos $1^{\circ}$ y $2^{\circ}$ del artículo 46 LGUC. e inciso final del artículo 21 b) LOCM.].

${ }^{15}$ Artículo 41 LGUC. 
La Circular dDu 55 señala que los planes seccionales son "un instrumento complementario, que no puede ser utilizado para modificar el Plan Regulador Comunal, y cuya principal función es establecer normas de diseño urbano referidas al espacio público, y eventualmente a las edificaciones, en los casos en que éstas no hubieran estado previstas en el nivel superior. Por la naturaleza de las materias que regula, puede ser el instrumento determinante del carácter de un barrio".

Los planes seccionales no sólo desarrollan el PRC o regulan de forma autónoma un sector acotado del territorio, sino también son necesarios en dos casos: i) para la declaración de una "zona de remodelación" (artículos 46 inciso $1^{\circ}$ y 72 inciso $1^{\circ}$ LGUC., y artículo 2.1.40. OGUC.); ii) para aprobar zonas de construcción obligatoria (artículo 46 inciso $1^{\circ}$ LGUC. y artículo 2.1.41. OGUC.). De esta manera los planes seccionales operan en los siguientes supuestos:

i) Para el desarrollo y detalle de los PRCs, donde adoptan la denominación de planos seccionales.

ii) Para la regulación detallada del uso del suelo ante la ausencia de PRCS.

iii) Para la declaración de zona de remodelación, y

iv) Para aprobar zonas de construcción obligatoria.

La aprobación de los planes seccionales se sujeta, en general, a un procedimiento similar al previsto para el PRC (artículo 2.1.15 ogUc.). Sin embargo, los planes seccionales de las zonas de remodelación y de construcción se deben aprobar por decreto supremo (artículos 2.1.39. y 2.1.40. OGUC.).

e) El límite urbano. El último instrumento de planificación que contempla la legislación urbanística chilena es el límite urbano. Según el artículo 52 LGUC. es una "la línea imaginaria que delimita las áreas urbanas y de extensión urbana que conforman los centros poblados, diferenciándolos del resto del área comunal".

La LGUC. considera al límite urbano como un instrumento de planificación territorial independiente y separado de los planes, y esto ocurre a pesar de que el límite urbano es fijado normalmente a través de los PRIs o los PRCS, como lo establece el artículo 54 LGUC.. Esto se debe a que el límite urbano puede ser establecido en comunas que no disponen de tales instrumentos (artículo 53 LGUC.), de manera que se podría afirmar que los PRIs y los PRCS suponen la determinación del límite urbano, pero éste no supone necesariamente a los primeros. Con la delimitación del área urbana se crea sólo una zona de usos, lo que es de escaso aporte en la planificación del territorio, por lo que su utilización es poco recomendable ${ }^{16}$.

${ }^{16}$ Vid. Circular DDU 55. 
La proposición del nuevo límite urbano o la modificación del límite urbano existente se someten al mismo procedimiento contemplado para la tramitación y aprobación de un PRC, previo informe de la SEREMI de Agricultura. Uno de los efectos más importante del límite urbano es la delimitación del "área urbana" y el "área rural" (artículo 52 LGUC.). En el área urbana se produce el mayor grado de intervención administrativa, pues los planes zonifican este espacio determinando los diversos usos del suelo permitidos, así como las actividades que se pueden realizar en ellos (residencial, equipamiento, actividades productivas, infraestructura, espacio público y área verde), estableciendo las correspondientes tipologías e intensidades de la construcción, a la vez que se pueden determinar zonas no edificables o de edificación restringida, por constituir un peligro potencial para los asentamientos humanos (artículo 60 LGUC.).

\section{LA ARTICULACIÓN DE LA COMPETENCIA URBANÍSTICA Y SECTORIAL}

\section{El deber general de "coordinación"17.}

El término coordinación se encuentra asentado en el Derecho positivo chileno, comenzando por la propia $\mathrm{CPR}^{18} \mathrm{y}$ pasando por la legislación administrativa chilena más relevante, v. gr., LOCBGAE. ${ }^{19}$, LOCGAR. ${ }^{20}$ y LOCM. ${ }^{21}$. Con dicha expresión se hace referencia a las relaciones interadministrativas que se dan a nivel del Estado y de las entidades territoriales. Este concepto se caracteriza, no obstante, por su ambivalencia, lo que acentúa la forma equívoca en que se utiliza y la dificultad para aprenderlo como concepto jurídico.

En una primera aproximación podemos encontrar un concepto ge-

${ }^{17}$ Sobre la materia se pueden consultar los interesantes estudios de MenÉndeZ Rexach, Angel, La cooperación, ¿un concepto juridico? en Documentación Administrativa 240 (octubre-diciembre, 1994), y de SÁnchez Morón, Miguel, La coordinación administrativa como concepto jurídico, en Documentación Administrativa 230231 (abril-septiembre, 1992). En relación al tema de este estudio son de interés los trabajos del mismo Menéndez Rexach, Angel, Coordinación de la ordenación del territorio con politicas sectoriales que inciden en el medio fisico, en Documentación Administrativa 230-231 (abril-septiembre, 1992), y La influencia de las infraestructuras en el desarrollo regional: problemas de coordinación, en Las economías regionales en la España de los 90 (Madrid, Colegio de Economistas, 1991).

${ }^{18}$ Vid. artículo 123.

${ }^{19}$ Vid. artículo 3 y 5 LOCBGAE.

${ }^{20}$ Vid. artículos 2 j); 17 b) y c); 18 b); 19 b); 24 m); 45 e); 62; 64 a), c) y f); 103, y 104 LOCGAR.

${ }^{21}$ Vid. artículos 7, 10 y 63 k) y l) LOCM. 
nérico de coordinación, que en algunos preceptos legales se utiliza como principio de la organización administrativa mediante el cual se persigue la integración de la diversidad de las partes o subsistemas en el conjunto o sistema administrativo, evitando contradicciones y reduciendo disfunciones que, de subsistir, impedirían o dificultarían respectivamente la realidad del sistema. En atención a esta finalidad intrínseca, la coordinación puede ser entendida como la fijación de medios y de sistemas de relación que hacen posible la información recíproca, la homogeneidad técnica en determinados aspectos y la acción conjunta de las diversas Administraciones públicas en el ejercicio de sus respectivas competencias, de tal modo que se logre la integración de actos parciales en la globalidad del sistema.

En el marco de este amplio y abstracto principio de coordinación hay que distinguir las dos variantes que podemos calificar de coordinación forzosa o coordinación en sentido estricto y de coordinación voluntaria o cooperación

En el primer caso, la coordinación forzosa o coordinación en sentido estricto supone la adopción por parte de un órgano de la Administración del Estado de una decisión de obligado cumplimiento para otro u otros órganos, que condiciona el ejercicio de sus propias competencias. Comprende, por tanto, un poder directivo de la Administración coordinante sobre las coordinadas, lo que significa que aquélla se encuentra respecto de éstas en una cierta posición de supremacía. Por tal razón, en un sistema de organización administrativa basado en la descentralización de varios de sus órganos, este poder de coordinación no puede presumirse con carácter general, sino que debe estar atribuido caso por caso por las normas jurídicas. Por su parte, la coordinación voluntaria o cooperación implica una conducta activa de los órganos de la Administración del Estado con el objeto de facilitar las actuaciones de los demás órganos de la Administración o para llevar a cabo acciones conjuntas y voluntariamente aceptadas para la consecución de sus fines de interés común. Es en este sentido que la cooperación constituye un deber general de los órganos de la Administración en los términos impuestos por la LOCBGAE.

La LOCBGAE. consagra la coordinación en este doble sentido. Primero, como principio básico de la organización administrativa (artículo 3, inciso $2^{\circ}$ ), y luego, como un deber general que se impone a todos los órganos de la Administración del Estado, en este caso, bajo la forma de cooperación. Así, estos órganos deben cumplir sus cometidos coordinadamente de forma de propender a la unidad de acción, evitando la duplicidad o interferencia de funciones, como lo ratifica los diversos preceptos de la LOCGAR. Y LOCM.

Resulta difícil hacer una tipificación de las diversas técnicas de coope- 
ración de las entidades de la Administración. Estas se concretan frecuentemente en informes, consultas, propuestas y, sobre todo, en acuerdos directos entre las diversas entidades. En la medida en que estas formas de coordinación se traducen en la imposición de una decisión en la actuación de los órganos públicos, nos encontramos ante una coordinación forzosa, como ocurre, por ejemplo, con los informes vinculantes o la resolución de conflictos de competencias.

El problema que existe en la actualidad en la Administración pública chilena es una tendencia a resolver las relaciones interadministrativas sobre la base del principio de competencia, asentada en una cultura que entiende que la satisfacción de los intereses colectivos y el cumplimiento de las responsabilidades por parte de las instancias públicas puede producirse siempre mediante el ejercicio diferenciado y unilateral de las correspondientes competencias, quedando en un segundo plano el principio de coordinación, especialmente en su vertiente cooperativa.

Además, el proceso de descentralización administrativa en Chile ha sido bastante lento y todavía se conservan los viejos esquemas de la Administración centralizada con una fuerte capacidad para intervenir en las entidades descentralizadas administrativamente e incluso autónomas, como ocurre con las municipalidades, a través del tradicional control de tutela. Así, por ejemplo, la LOCBGAE. canaliza los conflictos competenciales entre los órganos de los diversos órganos de la Administración, tanto centralizada como descentralizada, hacia la Administración central del Estado, al disponer en su artículo 39 que las contiendas de competencias que surjan entre diversas autoridades administrativas serán resueltas por el superior jerárquico del cual dependan o con el cual se relacionen. Ahora bien, tratándose de autoridades dependientes o vinculadas con distintos Ministerios (en definitiva, todos los órganos descentralizados funcional y territorialmente, como los Gobiernos regionales y las municipalidades), decidirán en conjunto los Ministros correspondientes, y si hubiere desacuerdo, resolverá el Presidente de la República. De esta forma, las relaciones interadministrativas se canalizan por la vía del deslinde competencial, que en caso de conflicto lleva a la propia Administración central a resolver estas cuestiones como instancia de coordinación.

Esta forma de resolver las relaciones interadministrativas se manifiesta en toda su expresión en la mentada cláusula de prevalencia que se aplica a los diversos instrumentos de planificación territorial, que se enmarca, en definitiva, en una suerte de principio general de preeminencia de las competencias del Estado frente a las entidades territoriales.

De esta forma, subyace la idea de que el orden constitucional se puede materializar y los diversos intereses públicos pueden ser satisfechos a partir 
de la actuación de la pluralidad de órganos de la Administración del Estado dentro de su propia esfera de competencias, como resultado de la simple adición o suma de dichas actuaciones, en la medida que su coherencia se encuentra garantizada por las reglas formales que lo rigen. Esto explica que en su funcionamiento los órganos de la Administración pública actúen de forma unilateral, preteriendo la combinación funcional de sus actuaciones para satisfacer determinados intereses públicos. Se trata de un modelo que no trasciende de la realidad de cada uno de estos órganos, evadiendo las instancias que permitan una actuación complementaria partiendo de sus propias diferencias.

La superación de una marcada centralización y una actuación administrativa anclada en la actuación unilateral constituye una de las materias más importantes que se deben enfrentar en la futura reforma de la organización administrativa chilena, con el objeto de articular y armonizar de forma enriquecedora los componentes decisionales diversos derivados de la pluralidad de competencias decisorias específicas. En definitiva, esto se debe traducir en un mayor desarrollo de las técnicas de cooperación en el marco de un gradual proceso de descentralización de la Administración del Estado, en donde los instrumentos de planificación territorial juegan un papel fundamental.

\section{Los mecanismos de "coordinación" entre la ordenación urbanistica y la} legislación sectorial.

Los mecanismos de coordinación previstos en la legislación chilena para articular la ordenación urbana con la legislación sectorial en materia de bienes públicos no escapan al cuadro general expuesto anteriormente. Se trata de instrumentos basados fundamentalmente en la coordinación forzosa, de escasa funcionalidad y de un pobre desarrollo normativo ${ }^{22}$.

Para analizar las formas de coordinación entre la ordenación urbanística y las competencias sobre los bienes públicos sectoriales debemos distinguir, en primer lugar, entre los bienes nacionales de uso público

${ }^{22}$ El tema ha sido tratado de la misma forma en el Derecho comparado. Así se puede ver, por ejemplo, los trabajos de Menéndez ReXach, Angel, Legislación de aguas, ordenación del territorio y medio ambiente, en Ley de aguas: análisis de la jurisprudencia constitucional (Madrid, MAP, 1991); Ortiz de Tena, María del Carmen, Planificación hidrológica (Madrid, Marcial Pons, 1994); SÁnchez Morón, Miguel, Planificación hidrológica y ordenación del territorio, en Revista de Administración Pública 123 (septiembre-diciembre, 1990); Pérez Moreno, Antonio, La ley de Costas y el planeamiento urbanistico, en Revista de Derecho Urbanistico 117 (marzo-abril, 1990); Parejo Alfonso, Luciano, Dominio público portuario y ordenación territorial: competencias del Estado y de las Comunidades Autónomas, en Revista de Derecho Urbanistico 135 (1993). 
naturales y artificiales.

Esta distinción es fundamental, en la medida que los bienes públicos naturales son una realidad que debe asumir la ordenación urbanística como algo propio del territorio, sin perjuicio de las competencias que se atribuyen a determinadas autoridades administrativas en su gestión y protección. Por su parte, los bienes públicos sectoriales se corresponden con las grandes infraestructuras que surgen de un meditado proceso de planificación, cuya integración dentro de la ordenación urbana es necesaria para garantizar el mejor aprovechamiento de los recursos de los órganos públicos implicados, a través de la unificación de criterios en la ejecución de las mismas.

a) Bienes nacionales de uso público natural. Son bienes nacionales de uso público natural: el mar adyacente (artículo 593 cc.), las playas (artículo 594 cc.), los álveos o lechos de ríos o lagos (artículo 30 cag.), los grandes lagos (inciso $1^{\circ}$ del artículo 596), las aguas que corren por cauces naturales (inciso $1^{\circ}$ del artículo 595 cc.y artículo $6^{\circ}$ CAg.).

La legislación chilena agrupa estos bienes en tres categorías: i) las costas y el mar territorial, que comprenden el mar adyacente, el fondo del mar y las playas de mar; ii) los ríos y lagos, que comprende el fondo del lago y su playa; y iii) los cauces o álveos de los ríos y lagos, esto es, el suelo por donde escurre el agua que cubre su paso ${ }^{23}$.

La administración de estos bienes se atribuye de la siguiente forma:

i) Corresponde a la Subsecretaría de Marina del Ministerio de Defensa Nacional, de acuerdo al DFL No 340 sobre Concesiones Marítimas, del año 1960 (en adelante DFLCM), y su Reglamento (DS. No 2 de 2005), el control, la fiscalización y supervigilancia de toda la costa y del mar territorial de la República. Esta función se ejerce especialmente a través de la Dirección General del Territorio Marítimo y de Marina Mercante. ${ }^{24}$ La Subsecretaría de Marina ejerce la facultad privativa de conceder el uso particular de las playas, terrenos de playa fiscales, de las rocas, fondos de mar, porciones de agua dentro y fuera de las bahías, como también de las playas, terrenos de playas y cauces de los "rios y lagos navegables por buques de más de cien toneladas" (artículo 10 DFLCM.).

ii) La Dirección General de Aguas, dependiente del Ministerio de

${ }^{23} \mathrm{El}$ artículo 30 inciso $1^{\circ} \mathrm{CAg}$. establece que "álveo o cauce natural de una corriente de uso público es el suelo que el agua ocupa y desocupa alternativamente en sus creces y bajas periódicas".

${ }^{24}$ Artículo 2 DS. No 2, Reglamento sobre Concesiones Maritimas de 2005, y artículo 3 m) DFL. No 292, Ley Orgánica de la Dirección del Territorio Marítimo y de Marina Mercante, de 1953. 
Obras Públicas, le corresponde la gestión y administración de los recursos hídricos, así como el otorgamiento de derechos reales de aprovechamiento de aguas que se encuentran en su cauce natural (ríos o lagos).

iii) A las Municipalidades les corresponde la administración de los cauces o álveos de los lagos y ríos no navegables por buques de más de cien toneladas existentes en el ámbito municipal [artículo 5 d) Locm.], así como la facultad para otorgar concesiones o permisos para su uso privativo.

iv) En el caso de la acuicultura y en la medida que implique el uso y aprovechamiento de bienes nacionales de uso público natural o, en su caso, de bienes fiscales, nuestro legislador ha hecho una distinción: a) en las áreas de playas de mar, terrenos de playa fiscales, porciones de agua y fondo, y rocas, dentro y fuera de las bahías, y en los ríos y lagos que sean navegables por buques de más de cien toneladas corresponde su administración a la Subsecretaría de Marina conforme se ha señalado en el primer apartado; y b) en el caso de los ríos y lagos no navegables por buques de más de cien toneladas, se desplaza a la Municipalidad y se le entrega la competencia a la Subsecretaría de Pesca del Ministerio de Economía. Sin embargo, en ambos casos se requiere una declaración administrativa previa de áreas apropiadas para el ejercicio de la acuicultura (artículo 67 LGPA.).

La cuestión es saber cómo inciden estas competencias sectoriales sobre la ordenación urbanística y cuáles son los mecanismos que existen para articularlas.

En primer lugar, las competencias municipales sobre los cauces o álveos de ríos no ofrecen, en principio, dificultades, porque estos bienes se encuentran en una situación idéntica respecto de los bienes públicos locales, de manera que no plantean mayores problemas para su integración en la ordenación urbanística. Así, la ordenación urbanística integrará el marco de legalidad que debe respetar y aplicar las municipalidades tanto en la administración de estos bienes, así como en la concesión de su uso privativo. En definitiva, se garantiza la unidad de acción administrativa por la identidad que existe en el sujeto actuante, en este caso la municipalidad ${ }^{25}$. Por su parte, también debemos tener presente que este organismo tiene una competencia residual respecto de los bienes públicos existente en la comuna, de tal forma que en el caso de ser atribuida su administración a

${ }^{25}$ Esto cobra particular importancia respecto de la extracción de áridos en los lechos y orillas de los ríos. En la práctica esta actividad se rige por dos tipos de normas municipales: i) Los PRC que pueden definir los lugares preferentes, estableciendo las zonas y normas para su explotación (vid. circular DDU 55); ii). Por las Ordenanzas Municipales sobre extración de áridos de bienes naciones de uso público, que regula la concesión de su uso privativo. 
otro órgano, desplaza las competencias municipales.

En dicho caso se encuentran las aguas terrestres, cuya administración está entregada a la Dirección General de Aguas. Tampoco éstas plantean dificultades, pues este régimen jurídico no interfiere en la ordenación urbanística. Esto se debe a que el sistema de asignación de los recursos hídricos existentes en Chile desde 1981, basado en la libre asignación y transferencia de los mismos, no considera ningún sistema de planificación hidrológica. Además, los proyectos, construcción y financiamiento de las modificaciones que fuere necesario realizar en cauces naturales o artificiales, con motivo de la construcción de obras públicas, urbanizaciones, edificaciones y otras obras en general, no están sujetas a ningún régimen especial impuesto por el Código de Aguas, salvo en lo que dice relación con algunas medidas de policía ${ }^{26}$. De esta forma, se aplican las normas generales que rigen este tipo de construcciones, dentro de las cuales se encuentra la legislación urbanística $^{27}$. La Dirección General de Aguas sólo se limita a gestionar y administrar los recursos hídricos y a conceder su aprovechamiento, pero no tiene competencia para conceder el uso privativo de los cauces o álveos de ríos, que es en definitiva el suelo por el cual discurren y que tiene más incidencia urbanística ${ }^{28}$.

En tercer y último lugar, llegamos a las competencias sobre las costas y

${ }^{26}$ El Código de Aguas, después de la modificación introducida por la Ley No 20.017 establece en su artículo 129 bis 2. que "la Dirección General de Aguas podrá ordenar la inmediata paralización de las obras o labores que se ejecuten en los cauces naturales de aguas corrientes o detenidas que no cuenten con la autorización competente y que pudieran ocasionar perjuicios a terceros, para lo cual podrá requerir el auxilio de la fuerza pública en los términos establecidos en el artículo 138 de este Código, previa autorización del juez de letras competente en el lugar en que se realicen dichas obras". La referencia que se hace con la expresión "autoridad competente" claramente alude, entre otras, a aquellas que deben velar por el cumplimientos de las normas contenidas en los planes reguladores.

${ }^{27}$ Así se desprende del artículo 41 cag. No obstante, en Chile se ha desarrollado una Política Nacional de Aguas que pretende obtener una gestión integrada de los recursos hídricos a nivel de cuencas, pero que todavía no se ha materializado.

${ }^{28}$ En el caso de las concesiones eléctricas regidas por el DFL. No 4/2007 LGSE., se debe mencionar que éstas otorgan el derecho para constituir servidumbres, pero no confiere por sí misma el derecho de aprovechamiento de las aguas, las cuales se deben tramitar conforme al cag. A su vez, tampoco otorgan el derecho para ocupar los bienes nacionales de uso público natural y excepcionalmente lo permite respecto de los bienes nacionales de uso público artificial (art. 16 LGSE.). Por su parte, tampoco se encuentran excluidas de la normativa urbanística, de manera que deben someterse a ella tanto en suelo urbano como rural. Sin lugar a dudas su análisis y estudio es de interés, ya que implica una intervención administrativa de diversa intensidad y naturaleza, que escapa a los límites de este estudio. 
el mar territorial, atribuida a la Subsecretaría de Marina, que tiene ciertos matices, pero que en definitiva tampoco plantean problemas competenciales.

La competencia de la Subsecretaría de Marina recae sobre las costas y el mar territorial. Sin embargo, ambos conceptos deben ser precisados.

Bajo la expresión costas se comprenden: i) Las playas, es decir, la extensión de tierra que las olas bañan y desocupan alternativamente hasta donde llegan en las más altas mareas (artículo 594 cc.), siendo bienes nacionales de uso público; ii) Los terrenos de playas, esto es, una franja de ochenta metros de ancho medidos desde la línea de más alta marea del litoral, y que son bienes fiscales o patrimoniales del Estado; iii) Las playas y terrenos de playas de los ríos y de los lagos navegables por buques de más de cien toneladas.

Por su parte, el mar territorial es el mar adyacente hasta la distancia de doce millas marinas medidas desde las respectivas líneas de base (artículo 593 cc.), comprendiendo las rocas, fondos de mar, porciones de agua dentro y fuera de las bahías (artículo $1^{\circ}$ DFLCM.).

El régimen urbanístico del suelo comprende también a las costas o litoral, de manera que éstas se encuentran sujetas a la clasificación del suelo (urbano o rural) y, en su caso, a los instrumentos de planificación territorial. Para explicar este asunto debemos distinguir la situación que se presenta en las áreas urbanas y rurales.

El artículo 64 LGUC. dispone expresamente que en las áreas urbanas, los bienes nacionales de uso público que correspondan a terrenos de playa o riberas de mar, de ríos y de lagos navegables, se usarán en concordancia con lo dispuesto en el Plan regulador y su Ordenanza local. De esta manera, estas zonas están sujetas a las normas de zonificación, ocupación, intensidad de la edificación y usos previstos en los instrumentos de planificación territorial. Por tal razón, el ejercicio de los usos privativos otorgados por la Subsecretaría de Marina deberá ser conforme con las normas contenidas en los planes reguladores, y de hecho el inciso $2^{\circ}$ del artículo 64 LGUC. dispone que las concesiones requerirán el informe previo favorable de la Dirección de Obras Municipales respectiva. Así, se establece un mecanismo de coordinación obligatoria, en este caso a favor autoridad municipal, que debe atenerse en todo caso a los diversos instrumentos de planificación territorial.

Respecto del área rural, la Subsecretaría de Marina ha sostenido en diversos informes que la limitación a los actos de disposición que le corresponde ejercer sobre los referidos bienes nacionales está circunscrita sólo a aquellos que se encuentran en sectores urbanos no comprendiendo a los situados en sectores rurales, por lo que solo puede concluirse, respecto de estos últimos, que su disposición por parte del Ministerio de Defensa no puede ser objeto 
de limitación alguna. Sin embargo, esto no se corresponde con el régimen de suelo rural previsto en el artículo 55 LGUC., que lo limita al uso agrícola, prohibiendo todo tipo de urbanización o formación de poblaciones. Más aún, toda subdivisión y urbanización de terrenos en dicho ámbito requiere de una autorización especial otorgada por la SEREMI de Agricultura, previo informe favorable de la SEREMI de Vivienda y Urbanismo, sin perjuicio de la aprobación que debe dar la Dirección de Obras Municipales respectiva. De esta forma, se requiere la aprobación conjunta de tres órganos de la Administración, lo cual es sin perjuicio del amplio margen de discrecionalidad de la cual disponen ante la falta de plan regulador que regule los usos y la edificación en el área rural ${ }^{29}$. Dada así las cosas, el régimen de las costas o litoral en el área rural no sólo está sujeto a la legislación urbanística, sino que es más estricto al momento de regular su uso y edificación.

En definitiva, tanto en el área urbana y rural la costa o litoral se encuentran plenamente integrado a la ordenación urbanística a través de instrumentos de coordinación obligatoria constituidos no sólo por los planes reguladores (área urbana), sino también por el informe vinculante que debe emitir la Dirección de Obras Municipales (área urbana) y la SEREMI de Vivienda y Urbanismo (área rural). Por tanto, los usos y la edificación del litoral se debe sujetar a la legislación urbanística y a los instrumentos de planificación territorial existentes, a pesar que comprenda bienes nacionales de uso público y que su uso privativo derive de un acto concesional. En el mismo sentido, pensamos que estas normas se deben aplicar a la actividad acuícola.

No obstante, a pesar de la gran importancia que tienen las áreas costeras en Chile, la regulación de los usos y edificación es claramente insuficiente y dista de favorecer un manejo integrado de tan valioso espacio. La actuación concurrente de los diversos órganos de la Administración del Estado sin un objetivo común ha generado una situación no del todo alentador. En los últimos años se ha tratado de superar estos problemas a través de una Política Nacional de Uso del Borde Costero del Litoral, como instancia de coordinación generada a partir del Gobierno central, que ha sido aprobada por Ds. No 475, de 11 de enero de 1998, del Ministerio de Defensa Nacional, Subsecretaría de Marina, con el objeto de efectuar una planificación integrada de los espacios marítimos y terrestres contiguos al litoral, propender a un uso equilibrado y compatible de las distintas actividades a desarrollar en esa área, y coordinar la actuación de los organismos y entidades públicas con competencias concurrente

${ }^{29}$ Lo dicho es sin perjuicio de que exista una PRDU o un PRI, que pueden establecer normas de uso y edificación del área rural, pero en la actualidad la existencia de tales instrumentos es excepcional. 
en dicho ámbito. Para tal efecto, se ha creado una Comisión Nacional integrada por los ministerios, organismos e instituciones de la Administración del Estado que tienen atribuciones sobre las actividades que puedan desarrollarse en las áreas costeras, cuyas funciones principales son las de proponer al Presidente de la República acciones que impulsen la Política Nacional, implementar dicha política y coordinar los diversos organismos públicos con competencias territoriales y sectoriales en el área costera. A su vez, mediante el Instructivo Presidencial No 1 de enero de 1997, se ha dispuesto la creación de Comisiones Regionales de Uso del Borde Costero, cuya función es la de proponer usos preferentes, apoyar la labor de la Comisión Nacional y realizar un Catastro Regional.

Este instrumento y su institucionalización constituyen un verdadero avance en el diseño de una política de ordenación racional del uso suelo desde una perspectiva que supere la visión local y sectorial. No obstante, el cumplimiento de los objetivos planteados excede con creces las posibilidades de los instrumentos utilizados hasta la fecha. El diseño de una política de protección del borde costero exige, en primer lugar, una revisión de la normativa sectorial que considere distintas zonas de protección y que condicionen, a su vez, a las normas horizontales, como ocurre con la ordenación urbanística. En segundo término, se deben contemplar a nivel legal modificaciones a la legislación urbanística que impongan al planificador la obligación de estructurar un sistema de accesos y espacios públicos que sea armónico con la zona costera. Por último, el paso más importante lo debe constituir la configuración de una competencia efectiva de ordenación territorial a nivel regional, que actúe como instancia de coordinación respecto de las competencias concurrentes a nivel local y sectorial, así como mecanismos de cooperación con los órganos de la Administración central, lo que está sujeto, no obstante, a un avance más profundo en proceso de descentralización administrativa que se viene impulsando en los últimos años.

b) Bienes nacionales de uso público artificial. Son bienes nacionales de uso público artificial básicamente los caminos públicos y la infraestructura asociada a ellos, como son los puentes y túneles (inciso $2^{\circ}$ del artículo 582 cc. y artículo $25^{\circ}$ LOMOp.). Como sabemos, si bien los puertos y aeropuertos son parte de las grandes infraestructuras, en Chile integran los bienes fiscales o patrimoniales del Estado, sin perjuicio de la incidencia que tienen sobre el territorio y, especialmente, respecto de la ordenación urbanística. Todas estas infraestructuras se comprenden bajo el concepto amplio de obras públicas.

Corresponde al Ministerio de Obras Públicas (en adelante Mop) el planeamiento, estudio, proyección, construcción, ampliación, repara- 
ción, conservación y explotación de las obras públicas fiscales (artículo $1^{\circ}$ Lomor.). Para tal efecto, se ha creado la Dirección General de Obras Públicas (DGOP) dependiente de dicho Ministerio, y que está formado, a su vez, por las Direcciones de Planeamiento, Arquitectura, Riego, Vialidad, Obras Portuarias y Aeropuertos ${ }^{30}$.

Si bien la LGUC. somete a licencia o permiso urbanístico a las urbanizaciones y construcciones del Estado, exime de esta obligación a las obras de infraestructuras que ejecute el Estado (artículo 116, inciso 4o). Esto no significa que existan otros mecanismos que articulen las competencias del Estado en relación con las grandes infraestructuras y la ordenación urbanística $^{31}$. En la materia que nos interesa, la Dirección de Planeamiento cumple una función fundamental. Si bien las diversas Direcciones tienen competencias en la planificación, construcción y conservación de las diferentes obras públicas, la Dirección de Planeamiento aparece como la máxima instancia coordinadora de dichas funciones al interior del mop.

La Dirección de Planeamiento es la instancia asesora estratégica del MOP en materias de planificación, definición de políticas, coordinación general y priorización de planes de estudios, proyectos y ejecución de las obras, de acuerdo a las necesidades del país, los programas gubernativos y los objetivos de los distintos servicios y unidades que comprende el quehacer ministerial. Por tanto, la planificación y, sobre todo, la priorización en la ejecución de obras públicas como carreteras, puertos y aeropuertos están entregada a esta Dirección. En el cumplimiento de estas funciones la Lомор. le impone expresamente a esta Dirección la observancia de los instrumentos de planificación de territorial, así como la coordinación de los planes del MOP con estos instrumentos. Así, el artículo 15 a) LOMOP. dispone que la Dirección de Planeamiento debe conformar sus objetivos con los Planes Nacionales de Desarrollo, los Planes Regionales y los Planes Reguladores e Intercomunales, es decir, con todo el bloque que integra los instrumentos de planificación territorial existentes en Chile. Por tal razón, esta Dirección debe evacuar las consultas que le formule el MINvu con el objeto de coordinar los planes y las necesidades del Ministerio de Obras Públicas con la planificación del desarrollo urbano (artículo 15 b).

Sin perjuicio de esta instancia de coordinación, existen también otros mecanismos a nivel regional y comunal. En primer lugar, se encuentran los convenios que pueden celebrar los Directores o Jefes de los Servicios

\footnotetext{
${ }^{30}$ Artículos 11 y 13 LOMOP.

${ }^{31}$ Esta excepción comprende, además, el no pago de los derechos municipales (DCGR Nos.11.986, de 27 de mayo de 1985). Además, esta norma se aplica no sólo los órganos del Estado, sino también a los concesionarios (DCGR No 17.860, de 10 de junio de 1997).
} 
Operativos Sectoriales del Ministerio de Obras Públicas en la Región respectiva con entidades u organismos regionales para la asesoría o ejecución de obras públicas en beneficio de la Región. ${ }^{32}$ En segundo lugar, los propios instrumentos de planificación territorial deben considerar la localización de las infraestructuras y su relación armónica entre su funcionamiento y la ciudad. Lo normal será que estas previsiones se realicen a nivel intercomunal o regional, pero cuando no hayan sido establecidas en dichos instrumentos, serán los Planes reguladores comunales los que deberán prever la localización de las grandes infraestructuras ${ }^{33}$.

Además de estos instrumentos de coordinación, no se debe olvidar lo previsto con carácter general en la LOCGAR. y LOCM. No obstante, la legislación chilena no prevé para estos casos ningún mecanismo de coordinación estricta u obligatoria en el caso en que los instrumentos de coordinación voluntaria llegan a fallar. No obstante, se debe recordar que en los niveles de planificación regional e intercomunal le corresponde una función relevante a los órganos de la Administración central del Estado, y la cláusula de prevalencia que rige respecto de los diversos instrumentos de planificación territorial permite imponer las obras de infraestructura a las previsiones de los Planes reguladores comunales.

${ }^{32}$ Artículo 61 No 11 LOMOP.

${ }^{33}$ La Planificación Urbana Regional debe orientar el desarrollo de los centros urbanos de las regiones a través de un Plan Regional de Desarrollo Urbano, que debe contener, entre otros documentos, unos lineamientos de desarrollo urbano regional, referidos, entre otros a la dotación de vías de comunicación terrestre, especialmente los caminos nacionales y las vías expresas, las vías ferroviarias, los puertos aéreos, marítimos, terrestres y los pasos fronterizos (artículo 2.1.5 oguc.). Por su parte, el Plan Regulador Comunal debe contener una Memoria Explicativa con, al menos, el diagnóstico de la totalidad del territorio comunal o del área afecta a planificación e identifique las vías estructurantes, en especial las vías colectoras y de servicio, indicando su relación con los caminos nacionales, las vías expresas y troncales, definidas en la planificación urbana regional e intercomunal, respectivamente (artículo 2.1.10. OGUC.). Por otra parte, dentro de los distintos tipos de uso previsto en la oGCU se contempla uno relativo a Infraestructuras, que se refiere a represas, puertos, aeropuertos, terminales de transporte terrestre, estaciones ferroviarias, centrales de generación o distribución de energía, plantas de captación, tratamiento o distribución de agua potable o de aguas servidas, vertederos y plantas de transferencia de basuras, centrales o estaciones de telecomunicaciones o instalaciones similares, las que podrán ser reguladas por los Instrumentos de Planificación Territorial mediante restricciones o indicaciones para el emplazamiento de determinadas instalaciones en zonas o subzonas del Plan, sin perjuicio de las demás normas legales y reglamentarias que procedan (Artículo 2.1.29. OGUC.). En las circulares del MINvU, DDU 26 y 55, se instruye en la elaboración de los PRIs y PRCs, estableciéndose una serie de pautas y criterios respecto de las infraestructuras, con referencia expresa a las carreteras, puertos y aeropuerto. 
En definitiva, se puede constatar como existen en la legislación chilena diversos mecanismos que permiten la integración de las obras de infraestructuras con la ordenación urbanística, a través de mecanismos de coordinación, tanto voluntaria como obligatoria (prevalencia). Sin embargo, también se debe reconocer que la regulación legal es ambigua en esta materia, y no concreta a través de instrumentos bien definidos sobre la forma en que se ha de cumplir el deber general de cooperación al cual se encuentran sujetos todos los órganos de la Administración del Estado. Es imperioso no sólo afrontar esta regulación respecto de las cuestiones que se plantean en materia urbanística y sectorial, sino también respecto de la acción administrativa general, pues la consagración a nivel de principios de la coordinación, como lo hace la LOCBAE, es claramente insuficiente.

\section{CONCLUSION}

La búsqueda del instrumento idóneo para garantizar el uso racional del suelo y la acción coordinada de las actuaciones públicas a nivel supralocal.

En los últimos años las políticas de ordenamiento territorial en Chile se han centrado en los clásicos instrumentos previstos en la legislación urbanística, sobre todo con el objeto de impulsar la planificación a nivel regional a través de los Planes Regionales de Desarrollo Urbano (PRDU).

En esta materia, la legislación urbanística chilena está claramente desfasada respecto del proceso de descentralización que ha experimentado la Administración pública durante la última década, manteniendo un sistema de planificación territorial de una enorme centralización. Además, los instrumentos de planificación a nivel supralocal son claramente insuficientes. Esto ocurre a pesar que se ha atribuido a los Gobiernos regionales desde 1993 diversas competencias en materias de ordenamiento territorial, pero que han carecido de los instrumentos adecuados para su materialización.

En este sentido, la implementación de una política de ordenamiento territorial sigue siendo impulsada desde el nivel central de la Administración. Así, en el año 1996 el Presidente de la República creó un Comité Interministerial de Desarrollo Urbano y Ordenamiento Territorial que tuvo por función el de servir de instancia preferente para el análisis e información de temas que sobrepasan el ámbito de cada Ministerio en particular y la generación de acuerdos entre aquellas Secretarías de Estado que cumplen funciones en ámbitos similares o relacionados entre sí, así como la de formular y proponer políticas de Gobierno en sus áreas respectivas, aprobar la idea de pre-legislar respecto de aquellos anteproyectos que corresponden al ámbito de sus competencias y coordinar la labor de 
los distintos órganos de la administración del Estado para posibilitar el cumplimiento de las acciones prioritarias del Ejecutivo ${ }^{34}$.

No obstante, los avances acaecidos en el último tiempo no han llegado al grado de implementar una ordenación integral del territorio, subsistiendo todavía problemas de coordinación administrativa y de conflictos en el uso del suelo que no encuentran soluciones satisfactorias

En este sentido, resulta imperioso la revisión de la legislación vigente con el objeto de introducir diversos mecanismos e instrumentos tendentes a racionalizar la acción pública y privada sobre el territorio y, en este sentido, cobra especial importancia la configuración en todos sus extremos de una competencia de ordenamiento territorial que sea la materialización efectiva del orden constitucional con incidencia física y, a la vez, la instancia de coordinación fundamental a nivel regional de la actuación pública sobre el territorio, asociado además a un proceso de descentralización territorial efectiva. Así, la ordenación del territorio será una función pública que debe dar una respuesta global a los problemas que plantea la utilización del espacio físico a través de la materialización de un determinado modelo territorial ${ }^{35}$.

Estos elementos nos permiten vincular la ordenación del territorio con el sistema constitucional material, pues esta función no es sino una concreción de los objetivos generales que le asigna el constituyente a los Gobiernos regionales (desarrollo social, cultural y económico de la región), siendo un instrumento esencial y presupuestos necesario para el logro de tales objetivos. Además, esto se corresponde con el principio básico que ha de regir las actuaciones de todos los órganos públicos en relación con el gobierno y administración interior del Estado, como es la búsqueda de

${ }^{34}$ Este Comité estaba coordinado por el Ministro de la Vivienda y Urbanismo y estaba compuesto por el Ministro Secretario General de la Presidencia, el Ministro de Planificación y Cooperación, el Ministro de Obras Públicas, el Ministro de Vivienda y Urbanismo, el Ministro de Agricultura, el Ministro de Transportes y Telecomunicaciones, el Ministro de Bienes Nacionales. Tenía, además, como invitados permanentes al Subsecretario de Desarrollo y Administrativo y al Director de Presupuesto. Sin embargo, la paulatina deserción de algunos ministros y subsecretarios fue una de las dificultades más críticas que enfrentó esta comisión. El objetivo fundamental, que era la aprobación de una política de desarrollo urbano y ordenamiento territorial, no registró avances concretos.

${ }^{35}$ Sobre la materia se puede consultar los trabajos de PÉrez Andrés, Antonio Alfonso. La ordenación del territorio, una encrucijada de competencias planificadoras, en Revista de Administración Pública 147 (septiembre-diciembre, 1998), y La ordenación del territorio en el Estado de las Autonomías (Madrid, Marcial Pons - Instituto Universitario de Derecho Público García Oviedo, 1998). 
un desarrollo territorial armónico y equitativo.

Es fundamental en la ordenación del territorio la coordinación que se da en diversos ámbitos:

i) En atención a su contenido (aspecto material), se deben conciliar factores físicos o espaciales con factores económicos y sociales.

ii) En atención a las Administraciones públicas, se deben armonizar sus actuaciones, tanto en el plano funcional (sectorial) como territorial, que exige la debida congruencia entre las políticas y planes de los diferentes niveles de decisión, como se prevé en los artículos 16, letras a) y e); 17 , letras b) y d); 18, letra a); 19, letra b); 21; 24, letras a) y e); 45, letras c) y e); y 72 inciso $1^{\circ}$, parte final, LOCGAR. lo que no es sino aplicación del principio de coordinación a que debe sujetarse la Administración del Estado (artículo 3.2 LOCBGAE.).

La ordenación del territorio se debe configurar como un título competencial radicada a nivel regional, traduciéndose en un conjunto de técnicas de coordinación con el objeto de articular las diversas políticas y competencias sobre el territorio. Así, por su carácter horizontal y, por tanto, función integradora, reclama para sí la armonización no sólo de las políticas sectoriales dentro de un mismo nivel de gobierno, sino de la política con repercusión física de los distintos niveles de gobierno.

En este sentido, los planes de ordenación urbana proyectados a nivel municipal deben quedar sujetos al contenido de los planes de ordenación del territorio y, por tanto, a todo el sistema de coordinación destinado a garantizar la cohesión y unidad de la acción administrativa sobre el territorio.

[Recibido el 31 de noviembre y aceptado el 19 de octubre de 2007].

\section{BIBLIOGRAFÍA}

Fernández, Tomás Ramón, Manual de Derecho Urbanistico (14º edición, Madrid, El Consultor, 1999).

Font I Llovet, Tomás, La protección del dominio público en la formación del Derecho administrativo español: potestad sancionadora y resarcimiento de daños, en Revista de Administración Pública 123 (septiembre-diciembre, 1990).

Font i LLovet, Tomás, La ordenación constitucional del dominio público, en MartínRetortillo, Sebastián (coordinador), Estudios sobre la Constitución Española, Homenaje al profesor Eduardo García de Enterría (Madrid, Civitas, 1991), I.

Figueroa Velasco, Patricio y Figueroa Valdés, Juan Eduardo, Urbanismo y Construcción (Santiago, LexisNexis, 2006).

García de Enterría, Eduardo y Fernández, Tomás-Ramón, Curso de Derecho 
Administrativo (9 edición, Madrid, Civitas, 1999).

García de Enterría, Eduardo - Parejo Alfonso, Luciano, Lecciones de Derecho urbanistico ( $2^{\circ}$ edición, Madrid, Civitas, 1981).

Menéndez ReXach, Angel, Coordinación de la ordenación del territorio con politicas sectoriales que inciden en el medio fisico, en Documentación Administrativa 230-231 (abril-septiembre, 1992).

MenÉndez ReXach, Angel, La configuración del dominio público maritimo-terrestre, en Ley de Costas. Legislación y jurisprudencia constitucional. Conferencias de las Jornadas sobre la Ley de Costas (Santiago de Compostela, Escola Galega de Administración Pública, 1992).

Menéndez Rexach, Angel, La cooperación, ¿un concepto juridico? en Documentación Administrativa 240 (octubre-diciembre, 1994).

Menéndez ReXach, Angel, La influencia de las infraestructuras en el desarrollo regional: problemas de coordinación, en Las economías regionales en la España de los 90 (Madrid, Colegio de Economistas, 1991).

MenÉndez ReXach, Angel, Legislación de aguas, ordenación del territorio y medio ambiente, en Ley de aguas: análisis de la jurisprudencia constitucional (Madrid, MAP, 1991).

Morillo-Velarde Pérez, José Ignacio, Dominio público (Madrid, Trivium, 1992).

Montt Oyarzún, Santiago, El Dominio público. Estudio de su régimen especial de protección y utilización (Santiago, ConoSur, 2001).

Ortiz de Tena, María del Carmen, Planificación hidrológica (Madrid, Marcial Pons, 1994).

Parada, José Ramón, Derecho Administrativo ( $8^{a}$ edición, Madrid, Marcial Pons, 2000), III.

Parejo Alfonso, Luciano, Derecho urbanistico. Instituciones básicas (Buenos Aires, Ciudad Argentina, 1986).

Parejo Alfonso, Luciano, Dominio público portuario y ordenación territorial: competencias del Estado y de las Comunidades Autónomas, en Revista de Derecho Urbanístico 135 (1993).

Parejo Alfonso, Luciano, Dominio público: un ensayo de reconstrucción de su teoría general, en Revista de Administración Pública, 100-102 (enero-diciembre, 1983).

PÉrez Andrés, Antonio Alfonso. La ordenación del territorio, una encrucijada de competencias planificadoras, en Revista de Administración Pública 147 (septiembrediciembre, 1998).

Pérez Andrés, Antonio Alfonso, La ordenación del territorio en el Estado de las Autonomías (Madrid, Marcial Pons -Instituto Universitario de Derecho Público García Oviedo, 1998).

Pérez Moreno, Antonio, La ley de Costas y el planeamiento urbanistico, en Revista de Derecho Urbanistico 117 (marzo-abril, 1990).

Ríos Alvarez, Lautaro, El urbanismo y los principios fundamentales del Derecho urbanistico (prólogo de Francisco González Navarro, Madrid, Ministerio para las Administraciones Públicas, 1985).

SÁnchez Morón, Miguel (dir.), Los bienes públicos. Régimen jurídico (Madrid, Tecnos, 1997).

SÁnchez Morón, Miguel, La coordinación administrativa como concepto jurídico, en Documentación Administrativa 230-231 (abril-septiembre, 1992). 
SÁnchez Morón, Miguel, Planificación hidrológica y ordenación del territorio, en Revista de Administración Pública 123 (septiembre-diciembre de 1990).

Vergara Blanco, Alejandro, La summa divisio de bienes y recursos naturales en la Constitución de 1980, en Navarro Beltrán, Enrique (coord.), 20 años de la Constitución chilena 1981-2001 (Santiago, ConoSur, 2001).

Vergara Blanco, Alejandro, La Teoría del Dominio Público. El estado actual de la cuestión, en Revista de Derecho Pública 114 (Madrid, 1989).

Vergara Blanco, Alejandro, Naturaleza jurídica de los "bienes nacionales de uso público", en Ius Publicum 3 (Santiago, 1999). 